\title{
Metodologia da pesquisa arqueológica: uma introdução
}

Denise Maria Cavalcante Gomes

Universidade Federal do Rio de Janeiro/Museu Nacional

AArqueologia teve um desenvolvimento heterogêneo na América Latina, produzindo linhas investigativas bastante distintas. Ainda assim, é vista no contexto mundial não como produtora, mas como consumidora de teorias e métodos originários no mundo anglo-saxão. No pós-guerra, a hegemonia dos Estados Unidos se fez sentir em diversos países latino-americanos, inclusive no Brasil, por meio do intercâmbio de pesquisadores voltados, sobretudo, à reconstrução histórico-cultural e às generalizações empíricas, o que resultou em um tipo de produção científica pouco reflexiva. Países como a Argentina trilharam caminhos distintos, desenvolvendo abordagens ecológicas no estudo das sociedades de caçadores-coletores, que assimilaram métodos processuais. No México, a promoção de ideias marxistas deu origem à Arqueologia Social, de considerável impacto na produção local.

De acordo com Politis (2003), a maior parte da pesquisa arqueológica praticada no continente, na última década, ainda era de feição histórico-cultural, embora viesse assimilando, gradualmente, influências teóricas e metodológicas das correntes processuais e pós-processuais. Essa mesma tendência foi observada anteriormente por Funari (1995), sendo descrita como uma forma de pluralismo teórico. O objetivo dessa coletânea é mostrar a vitalidade de 'nossa' Arqueologia, uma vez que diversos métodos originários nos centros politicamente hegemônicos vêm sendo utilizados de modo bastante criativo pelos arqueólogos ou ainda adaptados com sucesso a diferentes realidades regionais.

O dossiê "Metodologia da pesquisa arqueológica", destinado a arqueólogos profissionais, alunos de graduação e pósgraduação e pesquisadores em geral, reúne dez artigos que tratam de temas diversificados e que oferecem elementos possíveis de ser aplicados em outros contextos. Além de técnicas de campo, de análise e documentação da cultura material, alguns artigos apresentam dados inéditos obtidos a partir do emprego dos métodos descritos, enquanto outros discutem problemas metodológicos mais amplos, relativos a determinadas especialidades. Um dos trabalhos aborda o uso de métodos paleobotânicos na arqueologia de caçadores-coletores no México. Nove são contribuições brasileiras sobre sambaquis, bioarqueologia, arte rupestre, análise de artefatos cerâmicos históricos, levantamento intrassítio e levantamento regional na Amazônia.

O primeiro artigo traz importantes subsídios ao estudo dos processos formativos dos sambaquis do litoral, cuja abordagem proposta, denominada 'arqueologia estratégica', pode ser empregada na escavação de outros sítios monticulares, tais como os aterros e os tesos. Maria Dulce Gaspar, Daniela Klokler e Gina Faraco Bianchini sistematizam uma série de procedimentos de campo, aplicados pelas autoras em diversos sítios do litoral do Rio de Janeiro e de Santa Catarina. Embora sejam amplamente conhecidas pelos arqueólogos, essas técnicas possuem grande relevância ao possibilitar o acesso direto a amplos perfis estratigráficos a partir do aproveitamento de aberturas já existentes, decorrentes da antiga exploração da cal, da retirada de camadas para fins construtivos e de ações de vandalismo. De acordo com as autoras, o estudo dos perfis permite a identificação de áreas de atividade, além de orientar as intervenções subsequentes. Assim sendo, mais do que técnicas de campo, os métodos discutidos propiciam dados para a interpretação de diferentes comportamentos associados à construção de estruturas monticulares.

O segundo artigo, de Guillermo Acosta, Patrícia Pérez e Iran Rivera, tem por objetivo apresentar uma metodologia de estudo do processamento de plantas em sociedades de caçadores-coletores, desenvolvida a partir da investigação de

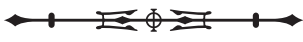


sítios na região de Chiapas, no sudoeste do México. Os autores adotam uma posição teórica associada ao materialismo histórico, que, segundo eles, possibilita a compreensão dos processos produtivos e ideológicos de transformação da natureza, e que permite apreender de modo mais amplo a importância da busca e do processamento de vegetais na vida cotidiana dos primeiros caçadores-coletores do território americano, contrariando antigas visões sobre a preponderância da caça entre essas populações. Um conjunto de técnicas é descrito, tais como flotação, recuperação de macrovestígios vegetais, análise de pólen, fitólitos, extração de microvestígios, análises químicas dos pisos de ocupação e traceologia lítica. Os resultados revelaram a presença de gêneros vegetais diversos, identificados nos contextos arqueológicos, com usos alimentícios, medicinais, rituais e na fabricação de artefatos.

O artigo de Sheila Mendonça de Souza e Claudia Rodrigues-Carvalho, sugestivamente intitulado "Ossos no chão", consiste numa discussão metodológica de procedimentos aplicados aos remanescentes humanos. Eles permitem resgatar, ainda em campo, antigos gestos e processos relacionados à deposição do morto. Os exemplos discutidos enfatizam a importância da observação dos vestígios humanos in situ, associados a outros elementos contextuais que evidenciam a preparação da área funerária, o seu uso posterior e os reflexos sobre a estrutura funerária. As autoras sustentam que, além das especificidades dos indivíduos, a área de sepultamento informa em níveis detalhados sobre o sítio e as atividades culturais nele desenvolvidas. Desse modo, é possível perceber a relevância que os estudos bioarqueológicos assumem, ao trazerem elementos que, integrados a outras evidências arqueológicas, oferecem novos parâmetros para as discussões acerca dos níveis de organização social e política de populações pretéritas.

Por sua vez, o artigo de Andrea de Lessa trata da importância de eleger e padronizar critérios de diagnóstico e registro documental sobre osteoartroses no contexto arqueológico brasileiro. A autora desenvolve sua discussão metodológica no âmbito dos estudos de marcadores de estresse ocupacional (MEO), os quais informam sobre atividades cotidianas, visando o entendimento do estilo de vida de populações do passado. São discutidos padrões osteológicos observados na análise de séries formadas por indivíduos adultos, provenientes de sítios que contribuem para questionar o modelo clássico de ocupação de sambaquis do litoral, baseado na subsistência por meio da coleta de moluscos e na ideia de alta mobilidade. Evidências de baixa mobilidade terrestre cotidiana e de lesões ligadas ao uso de remo, como correlatos de atividades vinculadas à mobilidade aquática e à pesca em alto mar, são interpretadas como sendo compatíveis com o paradigma atual, que considera a ocupação litorânea associada a uma estruturação sociocultural complexa, tendo como principal meio de subsistência a pesca, a ocupação permanente e a hierarquização dos assentamentos, e o desenvolvimento de expressiva densidade populacional.

Os dois artigos a seguir tratam de métodos utilizados na documentação de arte rupestre. Em diferentes regiões do mundo, a arte rupestre é considerada um testemunho precioso sobre os rituais e sistemas cosmológicos das populações do passado. Pelas mesmas razões históricas anteriormente mencionadas, a maior parte dos trabalhos sobre arte rupestre no Brasil teve como foco as classificações e definições cronoestilísticas, pouco adentrando às interpretações e deixando de lado a discussão sobre métodos e técnicas (Argüello Garcia, 2008). Os dois artigos preenchem esta lacuna, ao tratar do uso de novas tecnologias de registro em sítios rupestres amazônicos, o primeiro relativo a sítios com pinturas e o segundo, a sítios com gravuras.

O artigo de Edithe Pereira, Trinidad Martinez I Rubio e Carlos Augusto Palheta Barbosa apresenta o método de decalque digital, desenvolvido pela Universidade de Valência, na Espanha, e sua aplicação com sucesso em dois sítios com pinturas localizados em Monte Alegre, na Amazônia. Os autores descrevem as distintas etapas do método, que envolve a elaboração de um croqui dos painéis com os motivos e problemas apresentados, a documentação fotográfica,

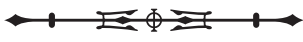


a recomposição espacial do painel com o uso de estação total, por meio do registro das três dimensões de cada um dos motivos, e, finalmente, a incorporação do painel à totalidade do sítio a partir da topografia. O texto representa uma contribuição aos estudos de arte rupestre, cujo detalhamento na exposição dos procedimentos e a avaliação realizada pelos autores permitem a sua replicação por outros pesquisadores.

Outros métodos foram empregados no que se refere às gravuras rupestres. A aplicação de tecnologias de registro e reprodução de gravuras rupestres é o tema do artigo de Renato Kipnis, Hélder Santos, Michelle Tizuka, Miguel Almeida e Mônica Corga. Os autores expõem uma metodologia que, de fato, conjuga procedimentos de registro tradicionais, tais como fotografia e realização de decalques com papel vegetal e lápis, ou com uso de tecido branco e carbono, às técnicas de laser scanning terrestre e fotogrametria de luz estruturada, para documentar e produzir modelos em 3D de centenas de gravuras rupestres localizadas na área do reservatório da Usina Hidrelétrica Santo Antônio, no rio Madeira, em Rondônia, que serão permanentemente inundadas.

Além da digitalização dos painéis rupestres, foram realizadas réplicas em resina - modelos tridimensionais de alta definição -, cuja vantagem é captar aspectos que não são visíveis a olho nu. O modelo digital do terreno pode, ainda, ser visualizado em diferentes escalas (no painel, no sítio e no vale do rio Madeira). Diversos usos são previstos para esses produtos, tais como a realização de animações e modelos virtuais, o que implica elementos a serem utilizados tanto nas pesquisas acadêmicas quanto na socialização mais ampla do conhecimento.

Os estudos cerâmicos também são representados no dossiê. Por meio de um enfoque interdisciplinar no âmbito da Arqueometria, duas diferentes classes de artefatos cerâmicos históricos, provenientes de sítios da região dos rios Macacu e Caceribu, em Itaboraí, Rio de Janeiro, são analisados no artigo de Cristiane Calza, Maria Dulce Gaspar, Danielle Dias, Filipe Coelho, Renata Pereira Freitas e Ricardo Tadeu Lopes. A proposta combina técnicas de Fluorescência de Raio-X, Microscopia Eletrônica de Varredura, Espectroscopia por Dispersão de Energia a estatísticas multivariadas, para estudar as peroleiras, supostamente fabricadas na Espanha entre os séculos XVI e XVIII e destinadas ao transporte de óleo de oliva e outros alimentos, cuja morfologia sugere uma descendência das ânforas mediterrâneas, e cachimbos cerâmicos atribuídos a descendentes de africanos, no contexto de ocupação colonial do recôncavo da baía de Guanabara.

O objetivo das análises é a caracterização dos artefatos por meio de sua composição físico-química, visando permitir inferências sobre a origem geográfica. Os resultados demonstram o grande potencial dessas técnicas, as quais, por meio da caracterização físico-química, não só estabelecem os possíveis centros de produção dos objetos, mas também auxiliam na interpretação arqueológica, pois, de um lado, informam sobre as relações de comércio entre o Brasil e o mundo Ibérico e, de outro, sobre as estratégias de autonomia de populações escravizadas.

O artigo de Denise Maria Cavalcante Gomes e José Gouvêa Luiz também representa uma forma interdisciplinar de produção do conhecimento arqueológico, a partir da aplicação da Geofísica, por meio do uso do Radar de Penetração no Solo (GPR) na prospecção intrassítio, realizada no sítio do Porto, em Santarém, Pará. Ainda que o emprego do método seja conhecido na Amazônia e remonte às pesquisas de Anna Roosevelt, realizadas na década de 1980 na ilha de Marajó, neste artigo os autores expõem de maneira sistemática os procedimentos adotados, os diferentes tipos de anomalias geofísicas testadas através de $24 \mathrm{~m}^{2}$ de escavações amostrais e sua correspondência arqueológica, enfatizando a importância dos resultados obtidos.

As anomalias revelaram feições antrópicas para deposição de lixo, fogueiras, áreas de produção de artefatos líticos e um enterramento secundário em urna cerâmica no espaço habitacional. Tendo em vista que uma das preocupações das pesquisas realizadas por Gomes na região é detalhar o contexto de uso dos objetos cerâmicos, não só os rituais,

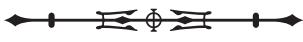


mas também aqueles relacionados às práticas de subsistência cotidianas, as informações reunidas permitiram ampliar o conhecimento sobre os espaços domésticos da cultura Santarém. Especialmente as feições antrópicas, que são buracos intencionalmente cavados para deposição de lixo comum, constituído por fragmentos de artefatos cerâmicos utilitários, lascas líticas, ossos de animais e carvão, e que estão relacionados a comportamentos de limpeza e manutenção da aldeia, consistem em dados relevantes, obtidos por meio do teste das anomalias geofísicas.

Vera Lúcia Calandrini Guapindaia e João Aires da Fonseca abordam uma forma de utilização do Sistema de Informação Geográfica (SIG) pouco comum na arqueologia brasileira, para delimitação e análise espacial de um importante sítio arqueológico na região do rio Trombetas - o Cipoal do Araticum, uma aldeia de interflúvio com características de assentamento ribeirinho no que tange à dimensão e à profundidade da terra preta -, cujas informações obtidas por meio dos métodos amostrais possibilitaram visualizar por meio de mapas a associação de diferentes variáveis relacionadas à localização, cor do solo, quantidade de artefatos, profundidade e topografia.

Os autores expõem os procedimentos de campo e os critérios de seleção das variáveis utilizadas na confecção do banco de dados, e correlacionam os resultados a um número considerável de datações inéditas. Surgem novas possibilidades de interpretação de uma longa sequência associada às ocupações Pocó e Konduri, com início por volta de 4000 A.P. e abandono em 530 A.P., que permitem fazer inferências sobre os processos formativos da terra preta ao longo do tempo e da morfologia circular da aldeia. Trata-se de informações de grande importância no que tange à cronologia do baixo Amazonas e à organização social dos grupos da região.

A aplicação do SIG ao levantamento arqueológico regional em três diferentes áreas na Amazônia é o tema do artigo de João Aires da Fonseca. Embora este uso do SIG seja amplamente conhecido no âmbito internacional, ele é relevante no contexto brasileiro e, em especial, na Amazônia, por estar relacionado à produção de modelos preditivos para a detecção de sítios em áreas densamente florestadas. Por meio do emprego de ferramentas de sensoriamento remoto e do SIG, o autor construiu modelos que associam distância dos recursos hídricos, declividade do terreno e altura do dossel da vegetação, produzindo mapas temáticos, a fim de indicar locais favoráveis para a existência de sítios arqueológicos. Os modelos foram testados em levantamentos realizados na região do rio Trombetas, em Carajás e no baixo Tocantins, produzindo resultados relevantes em diferentes ambientes.

Espera-se, a partir das contribuições dos diferentes artigos, incentivar novas formas de conhecimento do passado, que hoje são intimamente conectadas às agendas pós-processuais, no que tange à socialização da arqueologia. Os aportes aqui apresentados permitem, ainda, aprimorar a condução de projetos ligados ao gerenciamento do patrimônio arqueológico, com maior aproveitamento das informações geradas pelas pesquisas por parte das comunidades atuais. A reflexão sobre metodologia arqueológica também é um passo nesse sentido. Desejamos a todos uma boa leitura.

\section{REFERÊNCIAS}

ARGÜELLO GARCIA, Pedro Maria. Tendencias recientes en la investigación del arte rupestre en Suramérica: una síntesis crítica. Arqueología Suramericana, v. 4, n. 1, p. 33-75, 2008.

FUNARI, Pedro Paulo A. Mixed features of archaeological theory in Brazil. In: UCKO, P. (Ed.). Theory in Archaeology: a world perspective. London: Routledge, 1995. p. 232-246.

POLITIS, Gustavo. The theoretical landscape and methodological development of Archaeology in Latin America. Latin American Antiquity, v. 68, n. 2, p. 245-272, 2003.

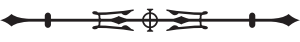

